\title{
Xenoposeidon is the earliest known rebbachisaurid sauropod dinosaur
}

\author{
Michael P Taylor Corresp. 1 \\ ${ }^{1}$ Department of Earth Sciences, University of Bristol, Bristol, England \\ Corresponding Author: Michael P Taylor \\ Email address: dino@miketaylor.org.uk
}

Xenoposeidon proneneukos is a sauropod dinosaur from the Early Cretaceous Hastings Group of England. It is represented by a single partial dorsal vertebra, NHMUK PV R2095, which consists of the centrum and the base of a tall neural arch. Despite its fragmentary nature, it is recognisably distinct from all other sauropods, and is here diagnosed with five unique characters. One character previously considered unique is here recognised as shared with the rebbachisaurid diplodocoid Rebbachisaurus garasbae from the midCretaceous of Morocco: an "M"-shaped arrangement of laminae on the lateral face of the neural arch. Following the more completely preserved Rebbachisaurus garasbae, these laminae are now interpreted as ACPL and lateral CPRL, which intersect anteriorly; and PCDL and CPOL, which intersect posteriorly. Similar arrangements are also seen in some other rebbachisaurid specimens (though not all, possibly due to serial variation), but never in non-rebbachisaurid sauropods. Xenoposeidon is therefore referred to Rebbachisauridae. Due to its inferred elevated parapophysis, the holotype vertebra is considered a midposterior dorsal despite its elongate centrum. Since Xenoposeidon is from the Berriasian-Valanginian (earliest Cretaceous) Ashdown Formation of the Wealden Supergroup of southern England, it is the earliest known rebbachisaurid by some 10 million years. Electronic 3D models were invaluable in determining Xenoposeidon's true affinities: descriptions of complex bones such as sauropod vertebrae should always provide them where possible. 


\section{Xenoposeidon is the earliest known rebbachisaurid sauropod 2 dinosaur}

3 Michael P. Taylor. Department of Earth Sciences, University of Bristol, Bristol BS8 1RJ,

4 England.

5 dino@miketaylor.org.uk

\section{Abstract}

8 Xenoposeidon proneneukos is a sauropod dinosaur from the Early Cretaceous Hastings Group of

9 England. It is represented by a single partial dorsal vertebra, NHMUK PV R2095, which consists of the centrum and the base of a tall neural arch. Despite its fragmentary nature, it is recognisably distinct from all other sauropods, and is here diagnosed with five unique characters. One character previously considered unique is here recognised as shared with the rebbachisaurid diplodocoid Rebbachisaurus garasbae from the mid-Cretaceous of Morocco: an "M"-shaped arrangement of laminae on the lateral face of the neural arch. Following the more completely preserved Rebbachisaurus garasbae, these laminae are now interpreted as ACPL and lateral CPRL, which intersect anteriorly; and PCDL and CPOL, which intersect posteriorly. Similar arrangements are also seen in some other rebbachisaurid specimens (though not all, possibly due to serial variation), but never in non-rebbachisaurid sauropods. Xenoposeidon is therefore referred to Rebbachisauridae. Due to its inferred elevated parapophysis, the holotype vertebra is considered a mid-posterior dorsal despite its elongate centrum. Since Xenoposeidon is from the Berriasian-Valanginian (earliest Cretaceous) Ashdown Formation of the Wealden Supergroup of southern England, it is the earliest known rebbachisaurid by some 10 million years. Electronic 3D models were invaluable in determining Xenoposeidon's true affinities: descriptions of complex bones such as sauropod vertebrae should always provide them where possible.

\section{Table of Contents}

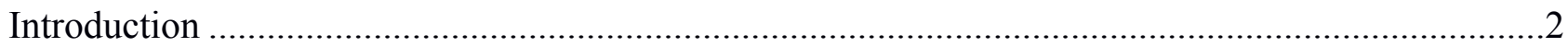

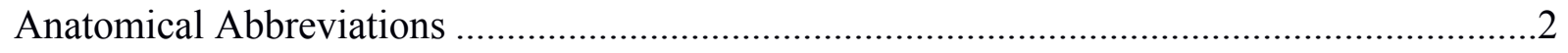

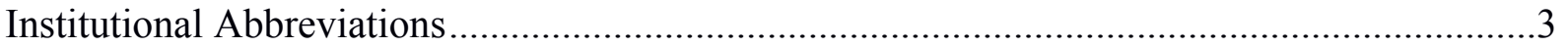

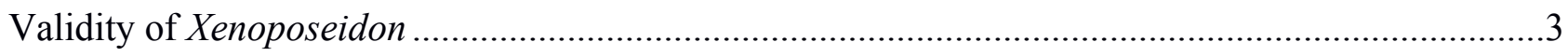

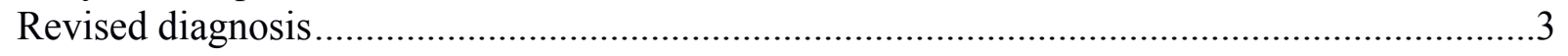

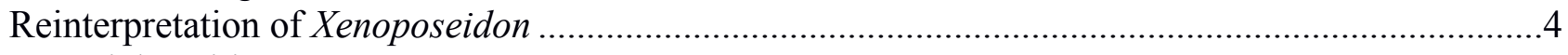

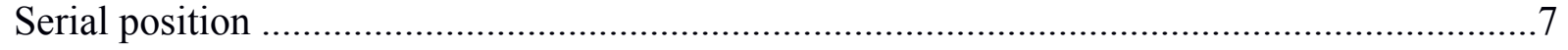

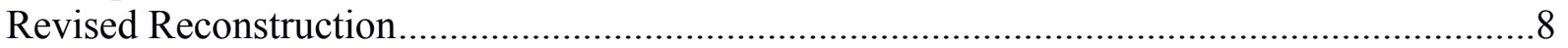

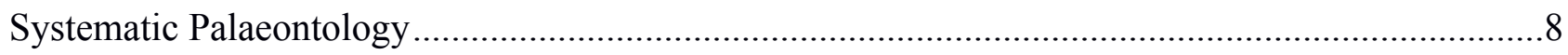

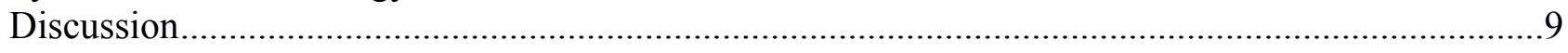

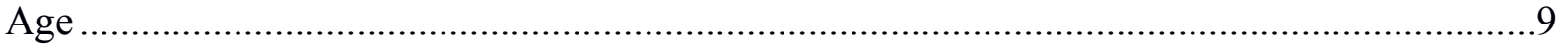

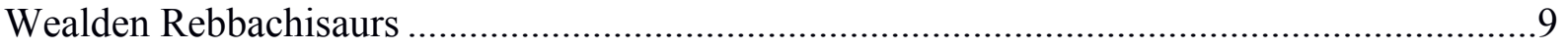

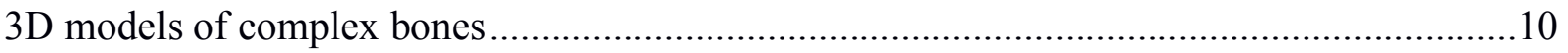

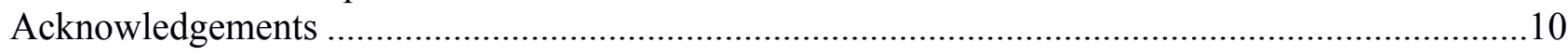




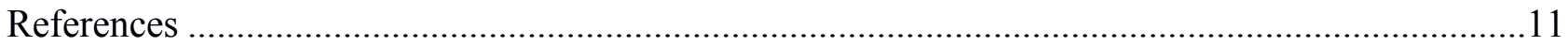

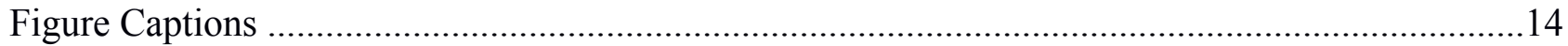

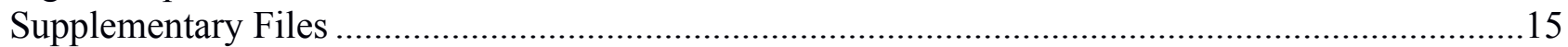

27 Introduction

28 The fossil record of sauropod dinosaurs extends through most of the Mesozoic, from the Late

29 Triassic (Lallensack et al. 2017) to the very end of the Cretaceous (e.g. Riera et al. 2009, Sellés

30 et al. 2016). However, their record in the earliest Cretaceous, as for most dinosaurs, is much less

31 rich (Tennant et al. 2017). In fact, almost the entire record of sauropodomorphs in the first three

32 ages of the Cretaceous rests on fossils from Europe (Tennant et al. 2018:figure 11:parts C-F) -

33 only Leinkupal from the Berriasian/Valanginian of Argentina (Gallina et al. 2014), and perhaps

34 Euhelopus (based on a revised age for the Mengyin Formation, Borinder et al. 2016) have been

35 named in this period from outside of Europe. In this context, sauropods from earliest Cretaceous

36 formations in Europe are particularly important for our understanding of the evolution of this

37 group.

38 Xenoposeidon proneneukos is a neosauropod sauropod dinosaur from the Berriasian-

39 Valanginian (earliest Cretaceous) Ashdown Formation of the Wealden Supergroup of southern

40 England (Taylor and Naish 2007). It is represented by a single partial mid-to-posterior dorsal

41 vertebra, NHMUK PV R2095 (Figure 1; BMNH R2095 at the time of the original description by

42 Taylor and Naish 2007; NHMUK R2095 at the time of Taylor 2017.). This element consists of

43 the centrum and the base of a tall neural arch, broken off below the transverse processes and

44 zygapophyses. Despite its fragmentary nature, it is recognisably different from all other

45 sauropods, and Taylor and Naish (2007) diagnosed it on the basis of six characters that they

46 considered unique among sauropods. Here, I will present a revised diagnosis.

47 Taylor and Naish (2007:1554-1557) compared the Xenoposeidon vertebra to those of the main

48 neosauropod groups - Diplodocoidea, Camarasauridae, Brachiosauridae and Titanosauria -

49 and concluded that it could not be convincingly referred to any of these groups (see Figure 2).

50 Their phylogenetic analysis (pp. 1157-1558 and figure 6) corroborated this by recovering

51 Xenoposeidon as a neosauropod in all most parsimonious trees, but in a polytomy with all other

52 neosauropods, wholly unresolved save that the clade Flagellicaudata was preserved in all MPTs.

53 In light of Wilson and Allain's (2015) redescription of the rebbachisaurid diplodocoid

54 Rebbachisaurus garasbae from the mid-Cretaceous of Morocco, and the availability of more photographs and models of rebbachisaurid material, it has now become possible to reinterpret the idiosyncratic system of laminae found in Xenoposeidon, and to refer it confidently to an existing family-level clade.

\section{Anatomical Abbreviations}

- aEI - average elongation index sensu Chure et al. (2010:384): length of a centrum divided by the average of the height and width of the posterior articular surface.

- ACPL - anterior centroparapophyseal lamina.

- CPOL - centropostzygapophyseal lamina.

- CPRF - centroprezygapophyseal fossa.

- CPRL - centroprezygapophyseal lamina. 
65

66

67

68

69

70

71

72

73

74

75

76

77

78

79

80

81

82

83

84

85

86

87

88

89

90

91

92

93

94

95

96

97

98

99

100

101

102

103

104

105

106

- EI - elongation index sensu Wedel et al. 2000: length of a centrum divided by the height of the posterior articular surface.

- PCDL - posterior centrodiapophyseal lamina.

- PCPL - posterior centroparapophyseal lamina.

- POSL — postspinal lamina.

- Postzyg - postzygapophysis.

- PPDL — paradiapophyseal lamina.

- Prezyg - prezygapophysis.

- PRPL - prezygaparapophyseal lamina.

- PRSL - prespinal lamina.

- SDL — spinodiapophyseal lamina.

\section{Institutional Abbreviations}

- GSGM - Gansu Geological Museum, Gansu Province, China.

- IWCMS - Isle of Wight County Museum Service at Dinosaur Isle, Sandown, Isle of Wight, England.

- HMN - Humboldt Museum für Naturkunde, Berlin, Germany.

- MB.R - Museum für Naturkunde Berlin, Berlin, Germany (fossil reptile collection).

- MIWG - Museum of Isle of Wight Geology (now Dinosaur Isle Visitor Centre), Sandown, Isle of Wight, England.

- $\quad$ MNHN - Muséum National d'Histoire Naturelle, Paris, France.

- NHMUK - the Natural History Museum, London, England.

- NMC - Canadian Museum of Nature (previously National Museum of Canada), Ottawa, Ontario, Canada.

- "WN" - "without number", an informal designation for specimens awaiting accession.

\section{Validity of Xenoposeidon}

Upchurch et al. (2011:497-498), in a review of Wealden sauropods, reassessed Xenoposeidon, accepting its validity and concurring with Taylor and Naish (2007) that it was difficult to place within any recognised sauropod clade. However, they tentatively proposed a basal somphospondylan identity for it. Similarly, Mannion et al. (2013:151) tentatively considered it most likely a basal macronarian.

D'Emic (2012:651) asserted that "the absence of diagnostic features renders Xenoposeidon a nomen dubium". However, his assessment was mistaken in several respects. For example, the extension of the base of the neural arch to the posterior extremity of the centrum is clearly not, as he asserted, due to damage. D'Emic claimed that dorsal vertebrae illustrated by Osborn and Mook (1921:plates LXIX and LXXII) have forward-sloping neural arches resembling those of Xenoposeidon: in reality, only one posterior dorsal vertebrae out of four complete dorsal columns illustrated in that monograph shows a forward slope, and it differs so much from its fellows that this can only be interpreted as the result of crushing. D'Emic further claimed that the lamina patterns observed in Xenoposeidon can be recognised in other sauropods, but I have been unable to find morphology resembling them in the descriptions he suggests: Osborn and Mook 1921 for Camarasaurus, Riggs 1903 for Brachiosaurus (probably a typo for Riggs 1904, which also does not depict similar patterns), Carballido et al. 2011 for Tehuelchesaurus. However, a similar 
107 pattern does appear in Rebbachisaurus, as will be discussed below. D'Emic (2012:651) is 108 probably correct that the "asymmetric neural canal" described by Taylor and Naish (2007:1553-

109 1554) is a misreading of the tall anterior fossa as being the anterior portion of the neural canal: as

110 Taylor and Naish pointed out, "The vacuity is filled with matrix, so the extent of its penetration

111 posteriorly into the neural arch cannot be assessed". Nevertheless, the shape and size of the fossa

112 is unique among sauropods, and it is bounded by laminae which do not seem to be medial

113 CPRLs - see below. In summary, as will be shown in more detail below, Xenoposeidon

114 proneneukos is a valid, diagnosable taxon, contra D'Emic (2012).

\section{Revised diagnosis}

116 Xenoposeidon differs from all other known sauropods in five respects. Compare the following

117 characters with the state in mid-posterior dorsal vertebra of other sauropods as shown in Figure

1182.

119 1. Neural arch covers dorsal surface of centrum. The posterior margin is continuous with that

120 of the centrum, such that in lateral view the posterior margin of the vertebra forms a single

121 smooth curve (Figure 3:1a, 1b). In most sauropod dorsals, the base of the neural arch is some

122 way forward of the posterior margin of the centrum. Even in Rebbachisaurus garasbae, where

123 the posterior margin of the neural arch approaches that of the centrum, there is a distinct kink in

124 lateral view between the posteroventral slope of the ventral part of the arch's posterior border,

125 and the vertical margin of the centrum (Figure 4B).

126 2. Neural arch slopes anteriorly 30-35 degrees relative to the vertical, as determined by the

127 orientation of the posterior articular surface of the centrum (Figure 3:2). In fully lateral view,

128 vertical orientation of the posterior articular surface is difficult to determine because the bone

129 extends slightly further posteriorly at centrum mid-height than more dorsally or ventrally, but it

130 is easy to see in a slightly posterolateral view, as can determined from the 3D model

131 (supplementary file 1).

132 3. Sharp oblique lamina above lateral fossa forms ventral border of a broad, flat area of

133 featureless bone. The fossa beneath this ridge-like lamina (Figure 3:3a) contains nested within it

134 a deeper lateral foramen; and above it, below the "M"-shaped complex of laminae that are

135 discussed in detail below, the bone is quite flat and smooth (Figure 3:3b).

136 4. Very large, teardrop-shaped anterior fossa, nearly as tall as the posterior articular facet of

137 the centrum and half as transversely broad as it is tall (Figure 3:4). In Rebbachisaurus garasbae,

138 the fossa is proportionally nearly as tall, but much narrower (Wilson and Allain 2015:figure 3E).

139 5. Arched laminae form vaulted boundary of anterior fossa. These laminae (Figure 3:5a)

140 cannot be interpreted as the medial CPRLs (Figure 3:5b), as those arise separately from the

141 neural arch pedicels. These laminae arising from the pedicels cannot instead be regarded lateral

142 CPRLs, as those laminae are located on the lateral face of the neural arch, as will be discussed

143 below. Furthermore, the point where the arched supporting laminae meet at the top of their arch

144 is located some way ventral to the location inferred for the prezygapophyses based on the

145 trajectory of the preserved portions of the medial CPRLs (Figure 5). 


\section{Reinterpretation of Xenoposeidon}

147 Taylor and Naish's (2007) history, geography, geology and description of the Xenoposeidon

148 specimen require no revision, and should continue to be considered definitive: this paper does

149 not supersede the earlier description, but should be read in conjunction with it.

150 The illustrations of the specimen in the original paper, however, were in monochrome and omitted the dorsal and ventral views. The present paper supplements these illustrations with a colour depiction from all six cardinal directions (Figure 1), an oblique view (Figure 5) and a high-resolution 3D model of the specimen (supplementary file 1).

More importantly, Taylor and Naish's (2007) interpretation of some features of the vertebra, particularly the " $\mathrm{M}$ "-shaped complex of laminae on the lateral faces of the neural arch, was mistaken. Although the neural spine and dorsal part of the neural arch are missing, including the pre- and postzygapophyses and lateral processes, they wrote that "sufficient laminae remain to allow the positions of the processes to be inferred with some certainty". But their inferences were incorrect. Taylor and Naish (2007:1553) interpreted the cross-shaped structure on the anterodorsal part of the left lateral face of the neural arch as the site of the parapophysis, despite the lack of any articular facet in that location. This influenced their interpretation of the four laminae that met at that point as the ACPL below, the PPDL above, the PRPL anteriorly and an unnamed accessory infraparapophyseal lamina posteroventrally, which they interpreted as homologous with a PCPL (Figure 6A). Similarly, they did not attempt to identify either the long lamina running up the posterior edge of the lateral face of the neural arch (designating it only "posterior lamina") or the lamina forming a shallow "V" with the "accessory infraparapophyseal lamina", simply calling it an "accessory postzygapophyseal lamina" (Figure 6A)

Among the various unusual features of the Xenoposeidon vertebra, the "M"-shaped set of laminae is immediately apparent in lateral view (Figure 4A): a line can be traced from the anterior margin of the neural arch's lateral face up the ACPL to the cross that was interpreted as the parapophysis, then posteroventrally down the "accessory infraparapophyseal lamina", then posterodorsally up the "accessory postzygapophyseal lamina" and finally down the posterior margin of the neural arch's lateral face, along the "posterior lamina". Photographs of other specimens that were available to us at this time did not apparently manifest similar features.

But subsequent work on Rebbachisaurus garasbae (Wilson 2012:100, figure 9; Wilson and Allain 2015) — and an associated video of the rotating vertebra (see acknowledgements) show that Rebbachisaurus has a similar complex of laminae (Figure 4B), which are described by Wilson and Allain (2015:6) as the second of the eight autapomorphies that they listed for the species: "infrazygapophyseal laminae (lat. CPRL, CPOL) that intersect and pass through neighbouring costal laminae (ACPL, PCDL) to form an ' $\mathrm{M}$ ' shape'.

Because the illustrated dorsal vertebra of Rebbachisaurus - MNHN MRS 1958 - is substantially complete, it is possible to follow the trajectories of the laminae that participate in the "M" to their apophyses, and so determine their true identities (Figure 4). The two vertically oriented laminae - the outer pillars of the "M" - continue up past the top of the "M". The anterior one supports the parapophysis, and the posterior supports the diapophysis. And the two laminae that form the valley in the middle of the " $\mathrm{M}$ " support the prezygapophysis and postzygapophysis: in both cases, as noted by Wilson and Allain, they intersect the vertical lamina before continuing to meet their respective zygapophyses. The four laminae that make up the 
189 "M", from anterior to posterior, are therefore the ACPL, posterior part of the lateral CPRL, 190 anterior part of the CPOL, and PCDL. Of these, the intersection between the ACPL and lateral 191 CPRL is clearly visible in left lateral view of MNHN MRS 1958 (Figure 4B). The intersection between the CPOL and PCDL is less apparent in this view, though clear in three dimensions. Both laminae continue dorsally beyond this intersection, but their paths are somewhat changed at the point of contact, with the dorsal portion of the PCDL inclining more anteriorly, and the rodlike CPOL apparently passing through the sheet of bone formed by the PCDL to meet the 196 postzygapophysis.

197 The referred Rebbachisaurus garasbae specimen NMC 50844 described and illustrated by Russell (1996:388-390 and figure 30) is also broadly consistent with this morphology. It is not possible to be definite about the laminar intersection based only on line drawings of the specimen from the four cardinal directions, but, as illustrated in Russell's figure 30c, the lateral CPRL does appear to pass through the ACPL. The CPOL seems in this specimen to originate posterior to the PCDL, not intersecting with it. But this difference from the holotype dorsal may be serial variation since, as Russell notes, the relatively longer centrum of his specimen indicates a more anterior serial position than for the holotype's dorsal vertebra; and this interpretation is corroborated by the observation than, based on lamina trajectories, the anteroposterior distance between the parapophysis and diapophysis was less in NMC 50844 than in the holotype.

In light of these Rebbachisaurus specimens, the mysterious laminae of Xenoposeidon are more readily explained. It is now apparent that the cross on the side of the Xenoposeidon vertebra is not the site of the parapophysis, as Taylor and Naish (2007:1553) proposed, but merely the intersection of two laminae that pass right through each other: the ACPL, running dorsolaterally, and the lateral CPRL, extending anterodorsally to the (missing) prezygapophysis (Figure 6B). Similarly, the "posterior lamina" is the PCDL, and it intersects with the CPOL, though the intersection is lost in NHMUK PV R2095 (Figure 6B). Both the parapophysis and diapophysis of the Xenoposeidon vertebrae would likely have been located some distance above the preserved portion, the former anterior to the latter.

It appears from Dalla Vecchia (1999:figure 47, left part) that in the holotype and only vertebra of Histriasaurus boscarollii, "WN-V6", the CPOL on the right side of the vertebra intersects with the PCDL in the same way as in Rebbachisaurus, though it is not possible to determine whether the lateral CPRL similarly intersects the ACPL. Dorsal vertebrae of other rebbachisaurid sauropods, however, do not appear to feature the distinctive "M" and intersecting laminae of Rebbachisaurus and Xenoposeidon:

- The 3D model of a dorsal vertebra of Nigersaurus (Sereno et al. 2007) shows that the lateral CPRLs originate anterior to the ACPLs and the CPOLs posterior to the PCDLs, so that there is no intersection. A subtle "V" shape does appear high up on the lateral faces of the neural arch, between the ACPL and the PCDL, but it seems unrelated to the lateral CPRL and CPOL.

- Unpublished 3D models of an anterior dorsal neural arch and a more posterior dorsal vertebra of Katepensaurus (pers. comm., Lucio M. Ibiricu) as illustrated in figures 3A and 5A of Ibiricu at el. (2017) show that in both vertebrae, the lateral CPRLs originate anterior to the ACPLs, and the CPOLs seem to originate posterior to the PCDLs though damage to the posterior portion makes the latter uncertain. 
232

233

234

235

236

237

238

239

240

241

242

243

244

245

246

247

248

249

250

251

252

253

254

255

256

257

258

259

260

261

262

263

264

265

266

267

268

269

270

271

272

273

274

- The laminae do not appear to intersect in the illustrated dorsal vertebra of Demandasaurus (Torcida Fernández-Baldor et al. 2011:figure 9).

- The sole known vertebra of Nopcsaspondylus seems to have an entirely different pattern of lamination (Mannion 2010:figure 5) with no lamina intersections like those of MNHN MRS 1958.

No determination can be made for other rebbachisaurids as they are insufficiently preserved or illustrated (e.g. Limaysaurus, Amazonsaurus, Cathartesaura), or simply lack posterior dorsal vertebral material (e.g. Rayososaurus, Tataouinea, Comahuesaurus, Zapalasaurus).

However, one cannot rule out the possibility that complete and well-preserved posterior dorsal vertebrae of most or all rebbachisaurids have Rebbachisaurus-like intersecting laminae: even in those species for which a well-preserved vertebra lacks them, this could be due to serial variation, with these features only fully developing in the more posterior dorsals.

Xenoposeidon, then, resembles Rebbachisaurus in the possession of a distinctive "M" on the lateral face of the neural arch, in the intersecting lateral CPRL and ACPL, and in the elevation of the parapophysis above the level of the prezygapophysis, as inferred from the trajectories of the lateral CPRL and ACPL - a complex of related features. Although at first glance they do not closely resemble each other, Xenoposeidon and Rebbachisaurus, while geometrically different, are topologically similar.

A superficially similar " $M$ "-shaped complex of laminae is also found in dorsal vertebrae of the saltasaurine titanosaur Neuquensaurus (Salgado et al. 2005:figures 3-4). However, this is not homologous to the situation in Rebbachisaurus and Xenoposeidon, as different laminae are involved: Salgado et al. (2005:626) identify the inner arms of the "M" as the PCPL and a novel accessory PCDL which they term the APCDL. (This APCDL, together with the ventral portion of the PCDL proper, constitute the "ventrally forked infradiapophyseal lamina" of Salgado et al. 1997). It is apparent from the illustrations of Salgado et al. (2005:figures $3 \mathrm{C}$ and especially 4AB) that the APCDL of Neuquensaurus is not contiguous with, and cannot be considered a part of, the CPOL.

Regarding the significance of the elevated parapophysis, since no complete or nearly complete rebbachisaurid dorsal column has been described, comparisons with other, better represented sauropods are warranted. In the probable basal diplodocoid Haplocanthosaurus, the dorsal margin of the parapophyseal facet reaches the level of, and is coincident with, the prezygapophyseal facet around dorsal vertebra 7 or 8 , but never rises any higher than this in more posterior vertebrae (Hatcher 1903:plate I). In the more distantly related diplodocid diplodocoids Apatosaurus and Diplodocus, the parapophysis never migrates far enough dorsally to reach a position level with the prezygapophyses, even in the most posterior dorsals (Gilmore 1936:plate XXV; Hatcher 1901:plates VII, VIII).

Taylor and Naish (2007:1554) argued that Xenoposeidon could not at that time be convincingly referred to Rebbachisauridae because Rebbachisaurus differs from NHMUK PV R2095 in five ways: "possession of a very prominent PCDL [mistranslated as PCPL in the original], large and laterally diverging prezygapophyses, depressions at the base of the neural arch (Bonaparte 1999:173), lateral foramina not set within fossae, and a strongly arched ventral border to the centrum". Of these features, the first is now recognised as occurring in Xenoposeidon; the second appears to be an outright error, as the prezygapophyses of Rebbachisaurus meet on the midline, 
275

276

277

278

279

280

281

282

283

284

285

286

287

288

289

290

291

292

293

294

295

296

297

298

299

300

301

302

303

304

305

306

307

308

309

310

311

312

313

314

315

316

317

318

and in any case the situation in Xenoposeidon is not known. "Depressions at the base of the neural arch" seems to be a mistranslation of Bonaparte's original Spanish, "profundas depresiones en la base de la espina neural", which refers not to the neural arch but the neural spine, and since this portion is not preserved in Xenoposeidon, it is not informative for our purposes. The 3D model of the Rebbachisaurus dorsal suggests that its lateral foramina are set in shallow depressions, but these are far less pronounced than those of Xenoposeidon. This leaves the stronger arching of the ventral border of the centrum in Rebbachisaurus, but this difference is not convincing given that the ventral margin of the NHMUK PV R2095 posterior cotyle is incomplete and the anterior end of the centrum is missing: the ventral border was likely rather more arched when the vertebra was complete

In conclusion, the weight of morphological evidence, including the camerate internal tissue structure of the centrum that is exposed in anterior view (Figure 1B), supports including Xenoposeidon within Rebbachisauridae. This is compatible with the observation of Taylor and Naish (2007:1557), in whose phylogenetic analysis "various most-parsimonious trees also recover Xenoposeidon in many other positions, including as a ... rebbachisaurid."

\section{Serial position}

The serial position of the Rebbachisaurus garasbae holotype dorsal vertebra MNHN MRS 1958 is not definitely known. However, it has been uniformly referred to as a posterior dorsal, most likely due to the very elevated position of its parapophyses and Lavocat's (1954) initial assessment of it as "une des dernières dorsales" (one of the last dorsals) - perhaps made with knowledge of the spatial relation of bones in the quarry.

The position of the Xenoposeidon proneneukos holotype vertebra NHMUK PV R2095 is of course even more difficult to determine in light of the limited nature of the specimen, though its similarity to MNHN MRS 1958 suggests a similar position. Taylor and Naish (2007:1553) wrote that "the high position of the parapophysis on the neural arch of R2095 indicates a mid to posterior placement of the vertebra within the dorsal column, but, because the prezygapophyses must have been dorsal to it, it was probably not among the most posterior vertebrae in the sequence." With the location of the parapophysis now interpreted as significantly higher than previously thought, and probably well above the prezygapophysis, an even more posterior position is indicated.

A posterior serial position is surprising in light of the anteroposterior length of the Xenoposeidon centrum. Its posterior articular surface measures $160 \mathrm{~mm}$ high by $170 \mathrm{~mm}$ wide, while the length of even the preserved portion of the centrum is $190 \mathrm{~mm}$, and it must have been at least $200 \mathrm{~mm}$ long when complete (Taylor and Naish 2007:table 1). As noted by Taylor and Naish (2007:1554), "the length of the centrum, especially in so posterior a dorsal vertebra, argues against [a diplodocoid identity]: the posterior dorsal centra of diplodocoids typically have EI < 1.0, compared with 1.25 for R2095" - or 1.21 using the aEI of Chure et al. (2010:384). However, rebbachisaurs may be unusual among diplodocoids in this respect - perhaps unsurprisingly, as they diverged early from the line leading to diplodocids, with their characteristically short dorsal centra, and likely retained something more similar to the ancestral neosauropod condition. Wilson and Allain (2015:8) give the centrum measurements of MNHN MRS 1958 as posterior height $231 \mathrm{~mm}$, posterior width $220 \mathrm{~mm}$ and length $220 \mathrm{~mm}$. This yields an aEI of 0.98 , meaning that the Xenoposeidon centrum is only $24 \%$ more elongate than that of Rebbachisaurus. This is a significant difference, but not an outlandish one. For comparison, the 
319 centrum of the basal rebbachisaurid Histriasaurus boscarollii holotype "WN-V6" is relatively 320 elongate, with its posterior articular surface measuring $150 \mathrm{~mm}$ high and centrum length of 321 "more than $200 \mathrm{~mm}$ " (Dalla Vecchia 1998:122) yielding an EI of $>1.33$. Also, the aEIs of the 322 last four dorsal vertebrae of the Brachiosaurus altithorax holotype FMNH PR 25107 are 1.34, $3231.27,1.19$ and 0.96 (calculated from the table of Riggs 1904:34): so aEIs of sauropod dorsals can

324 vary, within two serial positions of the same individual, from values below that of MNHN MRS 3251958 to above that of NHMUK PV R2095.

326 In conclusion, while the evidence regarding the serial position of NHMUK PV R2095 remains

327 equivocal, it suggests a more posterior position than previous inferred - it can be be fairly

328 confidently described as "posterior" within the broader "mid-to-posterior" designation — but it

329 is unlikely to be the very last dorsal.

\section{Revised Reconstruction}

331 In light of the reassignment of Xenoposeidon to Rebbachisauridae, and the reinterpretation of its

332 laminae, I present a new reconstruction of how the vertebra NHMUK PV R2095 might have

333 looked when complete (Figure 7). As in MNHN MRS 1958, the parapophysis and diapophysis

334 are both elevated above the zygapophyses. The lateral CPRL and ACPL meet at at a point where they project laterally about the same distance from the vertebra, as is apparent from the preserved portion of the vertebra; but the CPOL is assumed to pass through a sheet-like PCDL as in Rebbachisaurus, because it is clear from breakage in NHMUK PV R2095 that the PCDL extended further laterally from the body of the neural arch than the preserved portion indicates. The neural spine, composed as in Rebbachisaurus of pre- and post-spinal laminae together with the left and right SDLs, is shown fading out at the top, as there is no way to determine its height. The condyle that is the centrum's anterior articular surface is reconstructed as only slightly convex, as in Rebbachisaurus. It is shown almost immediately anterior to the preserved portion of the centrum, because the camerae in the dorsal part of the anteriormost preserved portion reach their point of dorsalmost excavation a short distance behind the front part, indicating that the cortex at this point was curving down over the camerae to form the condyle.

It is instructive to compare this with the original reconstruction of the vertebrae (Taylor and Naish:figure 5). The new reconstruction has a taller neural arch, a far more elevated parapophysis, a more posteriorly located diapophysis (no longer dorsal to the parapophysis) and a shallower condyle, as that of the original reconstruction was drawn with those of brachiosaurs in mind.

\section{Systematic Palaeontology}

352 Dinosauria Owen, 1842

353 Saurischia Seeley, 1888

354 Sauropodomorpha Huene, 1932

355 Sauropoda Marsh, 1878

356 Neosauropoda Bonaparte, 1986

357 Diplodocoidea Marsh, 1884

358 Rebbachisauridae Sereno et al., 1999

359 Xenoposeidon Taylor and Naish, 2007

360 Xenoposeidon proneneukos Taylor and Naish, 2007 
362 Holotype. NHMUK PV R2095, the Natural History Museum, London. A mid-to-posterior dorsal 363 vertebra consisting of partial centrum and neural arch.

364 Revised diagnosis: Differs from all other sauropods in the following characters:

365

366

367

368

369

370

371

372

373

374

375

376

377

378

379

380

381

382

383

384

385

386

387

388

389

390

391

392

393

394

395

396

397

398

399

400

401

402

1. Neural arch covers dorsal surface of centrum, with its posterior margin continuous with that of the centrum.

2. Neural arch slopes anteriorly $30-35$ degrees relative to the vertical.

3. Sharp oblique lamina above lateral fossa forms ventral border of a broad, flat area of featureless bone.

4. Very large, teardrop-shaped anterior fossa.

5. Arched laminae form vaulted boundary of anterior fossa, enclosed within the medial CPRLs.

\section{Discussion}

\section{Age}

As shown by Wilson and Allain (2015:table 1), the 19 then-recognised rebbachisaurids (of which 13 had been named) span the middle third of the Cretaceous. The earliest recognised taxon is Histriasaurus boscarollii from the upper Hauterivian or lower Barremian limestones of southwest Istria, Croatia (Dalla Vecchia 1998). Seven taxa, of which five are named, survived at least to the Cenomanian (earliest Late Cretaceous), of which two - Katepensaurus goicoecheai and Limaysaurus tessonei - may be from the Turonian (Ibiricu et al. 2013, Ibiricu et al. 2015, Salgado et al. 2004, Garrido 2010).

As discussed by Taylor and Naish (2007:1547-1548), the precise location and horizon where NHMUK PV R2095 was excavated were not recorded in the specimen's original brief description, which only said "the Wealden of Hastings" (Lydekker 1893:276). However, records of the collection of Philip James Rufford, who collected the specimen, indicate that the most likely location is Ecclesbourne Glen, a mile or two east of Hastings, East Sussex (see discussion in Taylor and Naish 2007:1548). The units exposed at Ecclesbourne Glen are part of the Ashdown Formation (formerly the Ashdown Beds Formation), which straddles the Berriasian/Valanginian boundary; but the part of the formation at that location is from the earlier Berriasian age. If this assessment is correct, then Xenoposeidon is from the very earliest Cretaceous, giving it an age of around 140 million years - about 10 million years earlier than Histriasaurus.

As the oldest known member of Rebbachisauridae, Xenoposeidon is an important taxon for understanding the evolution and palaeobiogeography of the group. The apparent paucity of rebbachisaurs in Gondwana during the early Early Cretaceous may merely be an artifact of an incomplete fossil record. On the other hand, the distribution of rebbachisaurids across South America and Africa in the mid-Cretaceous could represent the flowering of a ghost lineage extending back into the earliest Cretaceous or Late Jurassic in Europe, suggesting a migration from the northern supercontinent of Laurasia to the southern supercontinent of Gondwana.

Within Rebbachisauridae, the early age of Xenoposeidon is consonant with a basal position. However, further material will be required before numerical phylogenetic work can firmly establish its position within the group. 
403

404

405

406

407

408

409

410

411

412

413

414

415

416

417

418

419

420

421

422

423

424

425

426

427

428

429

430

431

432

433

434

435

436

437

438

439

440

441

442

443

444

445

\section{Wealden Rebbachisaurs}

Although Xenoposeidon is the first named rebbachisaurid from the Wealden Supergroup, other material from this unit has been referred to Rebbachisauridae. Naish and Martill (2001:plate 36, opposite page 236) illustrated some isolated sauropod teeth IWCMS.2001.201-203, and these were referred to Rebbachisauridae by Sereno and Wilson (2005:174). Mannion (2009) described a partial rebbachisaurid scapula MIWG 6544. Finally, Mannion et al. (2011) described a proximal caudal neural arch MIWG 5384, which they also interpreted as rebbachisaurid. All of these specimens are from the Barremian Wessex Formation of the Isle of Wight, so they could all belong to the same species or genus. However, since the likely Berriasian age of NHMUK PV R2095 makes it 10-15 Myr older than these specimens, it is unlikely that they belong to Xenoposeidon, but to some other as yet-unnamed rebbachisaurid. Thus is is likely that the Wealden Supergroup contains at least two rebbachisaurid sauropods.

\section{D models of complex bones}

Electronic 3D models were invaluable in determining Xenoposeidon's true affinities. Most obviously, the model of the Xenoposeidon vertebra itself, created by Heinrich Mallison (Palaeo3D), has functioned as an invaluable proxy for the fossil itself when I am unable to visit the NHMUK, and I have consulted it many times in writing this paper. I would also have been unable to determine to my own satisfaction whether the Katepensaurus dorsals feature intersecting laminae like those of Rebbachisaurus without the models provided by Lucio M. Ibiricu. Although no true model is available for the Rebbachisaurus dorsal itself or for the dorsal vertebrae of Nigersaurus, rotating videos were crucial in enabling me to understand their morphology. When interpreting specimens for which no such models exist, such as Russell's (1996) referred Rebbachisaurus specimen NMC 50844, the conclusions reached using only 2D representations - whether photographs or drawings — are much less well founded.

Techniques such as photogrammetry (see e.g. Falkingham 2012; Mallison and Wings 2014) are reducing the barriers to the creation of high-quality $3 \mathrm{D}$ models in full colour. Doing so is now inexpensive in both time and money. In light of our discipline's goal of making palaeontology more accessible and reproducible, then, it should become increasingly routine in the $21 \mathrm{st}$ Century to provide 3D models as a standard part of the description of complex bones such as sauropod vertebrae.

\section{Acknowledgements}

I thank Sandra D. Chapman (Natural History Museum, London) for access to the Xenoposeidon specimen, and Heinrich Mallison (Palaeo3D) who went far beyond the call of duty in building the 3D model of NHMUK PV R2095, supplying that of the Giraffatitan vertebra MB.R.3822, and talking me through aspects of photogrammetry. Lucio M. Ibiricu kindly provided access to unpublished 3D models of an anterior dorsal neural arch and a more posterior dorsal vertebra of Katepensaurus. I am also grateful to Jeff Wilson (University of Michigan) and Ronan Allain (Muséum National d'Histoire Naturelle, Paris) for sharing high-resolution photographs of the French Rebbachisaurus vertebra, and to Mathew J. Wedel (Western University of Health Sciences) and Darren Naish (University of Southampton) for helpful discussion. Phil Mannion (Imperial College London), Daniela Schwarz (Museum für Naturkunde Berlin) and Lucio M. Ibiricu provided constructive, detailed reviews that have helped to strengthen the arguments made herein; I also thank an additional anonymous reviewer. 
446 As noted in Taylor (2015), this project began when I recognised the true identity of the curious 447 laminae on the Xenoposeidon vertebra while viewing a rotating video of the Rebbachisaurus 448 garasbae holotype dorsal vertebra MNHN MRS 1958 on the University of Michigan Museum of 449 Paleontology's UMORF web-site (University of Michigan Online Repository of Fossils) at 450 https://umorf.ummp.lsa.umich.edu/wp/gallery/vertebrate-animations/. This video was based on a $4513 \mathrm{D}$ reconstruction created from CT scans performed at the AST-RX (Accèes Scientifique à la 452 Tomographie à Rayons X) of the MNHN by F. Goussard.

453

454

455

456

457

458

459

460

461

462

463

464

465

466

467

468

469

470

471

472

473

474

475

476

477

478

479

480

481

482

483

\section{References}

Bonaparte, Jose F. 1986. Les dinosaures (Carnosaures, Allosauridés, Sauropodes, Cétiosauridés) du Jurassique moyen de Cerro Cóndor (Chubut, Argentina). Annales de Paléontologie 72:325-386.

Bonaparte, Jose F. 1999. Evolucion de las vertebras presacras en Sauropodomorpha [Evolution of the presacral vertebrae in Sauropodomorpha]. Ameghiniana 36(2):115-87.

Borinder, Niclas H., Stephen F. Poropat and Benjamin P. Kear. 2016. Reassessment of the earliest documented stegosaurian fossils from Asia. Cretaceous Research 68:61-69.

Carballido, Jose L., Oliver W. M. Rauhut, Diego Pol and Leonardo Salgado. 2011. Osteology and phylogenetic relationships of Tehuelchesaurus benitezii (Dinosauria, Sauropoda) from the Upper Jurassic of Patagonia. Zoological Journal of the Linnean Society 163:605-662. doi:10.1111/j.1096-3642.2011.00723.x

Chure, Daniel, Brooks B. Britt, John A. Whitlock and Jeffrey A. Wilson. 2010. First complete sauropod dinosaur skull from the Cretaceous of the Americas and the evolution of sauropod dentition. Naturwissenschaften 97(4):379-91. doi:10.1007/s00114-010-0650-6

Dalla Vecchia, Fabio M. 1998. Remains of Sauropoda (Reptilia, Saurischia) in the Lower Cretaceous (Upper Hauterivian/Lower Barremian) Limestones of SW Istria (Croatia). Geologia Croatica 51(2):105-134.

Dalla Vecchia, Fabio M. 1999. Atlas of the sauropod bones from the Upper Hauterivian-Lower Barremian of Bale/Valle (SW Istria, Croatia). Natura Nascosta 18:6-41.

D'Emic, Michael D. 2012. The early evolution of titanosauriform sauropod dinosaurs. Zoological Journal of the Linnean Society 166:624-671.

Falkingham, Peter L. 2012. Acquisition of high resolution 3D models using free, open-source, photogrammetric software. Palaeontologia Electronica 15(1):1T. 15 pages. http://palaeoelectronica.org/content/issue1-2012technical-articles/92-3d-photogrammetry

Gallina, Pablo A., Sebastián Apesteguía, Alejandro Haluza and Juan I. Canale. 2014. A diplodocid sauropod survivor from the Early Cretaceous of South America. PLoS ONE 9:e97128.

Garrido, Alberto. C. 2010. Estratigrafía del Grupo Neuquén, Cretácico Superior de la Cuenca Neuquina (Argentina): nueva propuesta de ordenamiento litoestratigráfico. Revista del Museo Argentino de Ciencias Naturales 12:121-177. 
484 Gilmore, Charles W. 1936. Osteology of Apatosaurus with special reference to specimens in the 485 Carnegie Museum. Memoirs of the Carnegie Museum 11:175-300 and plates XXI-XXXIV.

486 Hatcher, Jonathan B. 1901. Diplodocus (Marsh): its osteology, taxonomy and probable habits, 487 with a restoration of the skeleton. Memoirs of the Carnegie Museum 1:1-63 and plates I-XIII.

488 Hatcher, J. B. 1903. Osteology of Haplocanthosaurus with description of a new species, and 489 remarks on the probable habits of the Sauropoda and the age and origin of the Atlantosaurus 490 beds; additional remarks on Diplodocus. Memoirs of the Carnegie Museum 2:1-75 and plates $491 \quad$ I-VI.

492 Huene, Friedrich von. 1932. Die fossile Reptile-Ordnung Saurischia, ihre Entwicklung und 493

494

495

496

497

498

499

500

501

502

503

504

505

506

507

508

509

510

511

512

513

514

515

516

517

518

519

520

521

522

523

Ibiricu, Lucio M., Matthew C. Lamanna, Rubén D.F. Martínez, Gabriel A. Casal, Ignacio A. Cerda, Gastón Martínez and Leonardo Salgado. 2017. A novel form of postcranial skeletal pneumaticity in a sauropod dinosaur: Implications for the paleobiology of Rebbachisauridae. Acta Palaeontologica Polonica 62(2):221-236. doi:10.4202/app.00316.2016

Ibiricu, Lucio M., Gabriel A. Casal, Rubén D. Martínez, Matthew C. Lamanna, Marcelo Luna and Leonardo Salgado. 2013. Katepensaurus goicoecheai, gen. et sp. nov., a Late Cretaceous rebbachisaurid (Sauropoda, Diplodocoidea) from central Patagonia, Argentina. Journal of Vertebrate Paleontology 33(6):1351-1366. doi:10.1080/02724634.2013.776562

Ibiricu, Lucio M., Gabriel A. Casal, Rubén D. Martínez, Matthew C. Lamanna, Marcelo Luna and Leonardo Salgado. 2015. New material of Katepensaurus goicoecheai (Sauropoda: Diplodocoidea) and its significance for the morphology and evolution of Rebbachisauridae. Ameghiniana 52:430-446. doi:10.5710/AMGH.24.04.2015.2830

Lallensack, Jens N., Hendrik Klein, Jesper Milàn, Oliver Wings, Octávio Mateus and Lars B. Clemmensen. 2017. Sauropodomorph dinosaur trackways from the Fleming Fjord Formation of East Greenland: Evidence for Late Triassic sauropods. Acta Palaeontologica Polonica 62(4):833-843.

Lavocat, René J. M. 1954. Sur les Dinosauriens du continental intercalaire des Kem-Kem de la Daoura. [On the dinosaurs of the Continental Intercalaire of the Kem Kem of the Daoura]. Comptes Rendus 19th International Geological Congress 1952(1):65-68. English translation by Matthew C. Lamanna provided by the Polyglot Paleontologist at http://paleoglot.org/files/Lavocat 54.pdf

Li, Li-Guo, Da-Qing Li, Hai-Lu You and Peter Dodson. 2014. A new titanosaurian sauropod from the Hekou Group (Lower Cretaceous) of the Lanzhou-Minhe Basin, Gansu Province, China. PLOS ONE 9(1):e85979. doi:10.1371/journal.pone.0085979

Lydekker, Richard. 1893. On a sauropodous dinosaurian vertebra from the Wealden of Hastings. Quarterly Journal of the Geological Society, London 49:276-280.

Mallison, Heinrich, and Oliver Wings. 2014. Photogrammetry in paleontology - a practical guide. Journal of Paleontological Techniques 12:1-31.

Mannion, Philip D. 2009. A rebbachisaurid sauropod from the Lower Cretaceous of the Isle of Wight, England. Cretaceous Research 30:521-526. doi:10.1016/j.cretres.2008.09.005 
524 Mannion, Philip D. 2010. A revision of the sauropod dinosaur genus 'Bothriospondylus' with a

525

526

527

528

529

530

531

532

533

534

535

536

537

538

539

540

541

542

543

544

545

546

547

548

549

550

551

552

553

554

555

556

557

558

559

560

561

562 redescription of the type material of the middle jurassic form 'B. madagascariensis'. Palaeontology 53(2):277-296. doi:10.1111/j.1475-4983.2009.00919.x

Mannion, Philip D., Paul Upchurch and Stephen Hutt. 2011. New rebbachisaurid (Dinosauria: Sauropoda) material from the Wessex Formation (Barremian, Early Cretaceous), Isle of Wight, United Kingdom. Cretaceous Research 32(6):774-780. doi:10.1016/j.cretres.2011.05.005

Mannion, Philip D., Paul Upchurch, Rosie N. Barnes and Octávio Mateus. 2013. Osteology of the Late Jurassic Portuguese sauropod dinosaur Lusotitan atalaiensis (Macronaria) and the evolutionary history of basal titanosauriforms Zoological Journal of the Linnean Society 168(1):98-206. doi:10.1111/zoj.12029

Marsh, Othniel C. 1878. Principal characters of American Jurassic dinosaurs, part I. American Journal of Science (Series 3) 16:411-416.

Marsh, Othniel C. 1884. Principal characters of American Jurassic dinosaurs. Part VII. On the Diplodocidae, a new family of the Sauropoda. American Journal of Science, series 3, 27:160168.

Naish, Darren, and David M. Martill. 2001. Saurischian dinosaurs I: Sauropods. pp. 185-241 in: Martill, David M., and Darren Naish (eds.). Dinosaurs of the Isle of Wight. Palaeontological Association, London.

Osborn, Henry Fairfield, and Charles C. Mook. 1921. Camarasaurus, Amphicoelias and other sauropods of Cope. Memoirs of the American Museum of Natural History, new series 3(3):247-387, and plates LX-LXXXV.

Owen, Richard. 1842. Report on British fossil reptiles, Part II. Reports of the British Association for the Advancement of Science 11:60-204.

Riera, Violeta, Oriol Oms, Rodrigo Gaete and Àngel Galobart. 2009. The end-Cretaceous dinosaur succession in Europe: The Tremp Basin record (Spain). Palaeogeography, Palaeoclimatology, Palaeoecology 283:160-171. doi:10.1016/j.palaeo.2009.09.018

Riggs, Elmer S. 1903. Brachiosaurus altithorax, the largest known dinosaur. American Journal of Science 15(4):299-306.

Riggs, Elmer S. 1904. Structure and relationships of opisthocoelian dinosaurs. Part II, the Brachiosauridae. Field Columbian Museum, Geological Series 2(6):229-247, plus plates LXXI-LXXV.

Russell, Dale A. 1996. Isolated dinosaur bones from the Middle Cretaceous of the Tafilalt, Morocco. Bulletin du Muséum National d'Histoire Naturelle, 4ème série - section C: Sciences de la Terre, Paléontologie, Géologie, Minéralogie 18(2-3):349-402.

Salgado Leonardo, Rodolfo A. Coria and Jorge O. Calvo. 1997. Evolution of titanosaurid sauropods. I: Phylogenetic analysis based on the postcranial evidence. Ameghiniana 34:3-32.

Salgado, Leonardo, Alberto Garrido, Sergio E. Cocca and Juan R. Cocca. 2004. Lower Cretaceous rebbachisaurid sauropods from Cerro Aguada Del León (Lohan Cura Formation), 
563

564

565

566

567

568

569

570

571

572

573

574

575

576

577

578

579

580

581

582

583

584

585

586

587

588

589

590

591

592

593

594

595

596

597

598

599

600

601

602

Neuquén Province, Northwestern Patagonia, Argentina. Journal of Vertebrate Paleontology 24(4):903-912. doi:10.1671/0272-4634(2004)024[0903:LCRSFC]2.0.CO;2

Salgado, Leonardo, Sebastián Apesteguía and Susana E. Heredia. 2005. A new specimen of Neuquensaurus australis, a Late Cretaceous saltasaurine titanosaur from North Patagonia. Journal of Vertebrate Paleontology 25(3):623-634.

Seeley, Harry G. 1888. On the classification of the fossil animals commonly named Dinosauria. Proceedings of the Royal Society of London 43:165-171.

Sereno, Paul C., and Jeffrey A. Wilson. 2005. Structure and evolution of a sauropod tooth battery. pp. 157-177 in: Wilson, Jeffrey A., and Kristina Curry-Rogers (eds.), The Sauropods: Evolution and Paleobiology. University of California Press, Berkeley.

Sellés, Albert G., Josep Marmi, Sergio Llácer and Alejandro Blanco. 2016. The youngest sauropod evidence in Europe. Historical Biology 28(7):930-940. doi:10.1080/08912963.2015.1059834

Sereno, Paul C, Jeffrey A. Wilson, Lawrence A. Witmer, John A. Whitlock, Abdoulaye Maga, Oumarou Ide, Timothy A. Rowe. 2007. Nigersaurus taqueti (On-line), Digital Morphology. Accessed November 14, 2017 at http://digimorph.org/specimens/Nigersaurus taqueti/dorsal_vertebra/

Sereno, Paul C., Allison L. Beck, Didier. B. Dutheil, Hans C. E. Larsson, Gabrielle. H. Lyon, Bourahima Moussa, Rudyard W. Sadleir, Christian A. Sidor, David J. Varricchio, Gregory P. Wilson and Jeffrey A. Wilson. 1999. Cretaceous sauropods from the Sahara and the uneven rate of skeletal evolution among dinosaurs. Science 282:1342-1347.

Taylor, Michael P. 2015. Is Xenoposeidon a rebbachisaur? Sauropod Vertebra Picture of the Week, July 14, 2015. Accessed November 15, 2017 at https://svpow.com/2015/07/14/is$\underline{\text { xenoposeidon-a-rebbachisaur/ }}$

Taylor, Michael P. 2017. Xenoposeidon is ten years old today! And it's the oldest rebbachisaur! Sauropod Vertebra Picture of the Week, November 15, 2017. Accessed June 10, 2018 at https://svpow.com/2017/11/15/xenoposeidon-is-ten-years-old-today-and-its-the-oldestrebbachisaur/

Taylor, Michael P., and Darren Naish. 2007. An unusual new neosauropod dinosaur from the Lower Cretaceous Hastings Beds Group of East Sussex, England. Palaeontology 50(6):15471564. doi: 10.1111/j.1475-4983.2007.00728.x

Tennant, Jonathan P., Alfio Alessandro Chiarenza and Matthew Baron. 2018. How has our knowledge of dinosaur diversity through geologic time changed through research history? PeerJ 6:e4417. Doi:10.7717/peerj.4417

Tennant, Jonathan P., Philip D. Mannion, Paul Upchurch, Mark D. Sutton and Gregory D. Price. 2017. Biotic and environmental dynamics across the Late Jurassic-Early Cretaceous transition: evidence for a protracted period of faunal and ecological turnover. Biological Reviews 92:776-814. doi:10.1111/brv.12255

Torcida Fernández-Baldor, Fidel, José Ignacio Canudo, Pedro Huerta, Diego Montero, Xabier Pereda Suberbiola and Leonardo Salgado. 2010. Demandasaurus darwini, a new 
603

604

605

606

607

608

609

610

611

612

613

614

615

616

617

\section{Figure Captions}

619

620

621

622

623

624

625

626

627

628

629

630

631

632

633

634

635

636

637

638

639

640

641

642

643

644 45(4):343-388.

rebbachisaurid sauropod from the Early Cretaceous of the Iberian Peninsula. Acta Palaeontologica Polonica 56(3):535-552. doi:10.4202/app.2010.0003

Upchurch, Paul, Philip D. Mannion and Paul Barrett. 2011. Sauropod Dinosaurs. pp. 476-525 in: David J. Batten (ed.), English Wealden Fossils (No. 14 in Field Guides to Fossils series), ISBN 978-1-4443-6711-9. The Palaeontological Association. 769 pp.

Wedel, Mathew J., Richard L. Cifelli and R. Kent Sanders. 2000. Osteology, paleobiology, and relationships of the sauropod dinosaur Sauroposeidon. Acta Palaeontologica Polonica

Wilson, Jeffrey A. 2012. New vertebral laminae and patterns of serial variation in vertebral laminae of sauropod dinosaurs. Contributions from the Museum of Paleontology, University of Michigan 32(7):91-110. http://hdl.handle.net/2027.42/92460

Wilson, Jeffrey A., and Ronan Allain. 2015. Osteology of Rebbachisaurus garasbae Lavocat, 1954, a diplodocoid (Dinosauria, Sauropoda) from the early Late Cretaceous-aged Kem Kem beds of southeastern Morocco. Journal of Vertebrate Paleontology 35(4):e1000701. Doi:10.1080/02724634.2014.1000701

Figure 1. NHMUK PV R2095, the holotype and only vertebra of Xenoposeidon proneneukos, shown from all six cardinal directions. Top row: A. dorsal view, with anterior to the left. Middle row, left to right: B. anterior, C. left lateral, D. posterior and E. right lateral view. Bottom row: F. ventral view, with anterior to the left. Scale bar $=200 \mathrm{~mm}$.

Figure 2. Comparative morphology of mid-posterior dorsals from six sauropods: Xenoposeidon and five representatives of major groups. Each vertebra is shown in anterior and left lateral (or right lateral reversed) views, scaled to the same centrum height. Parts $\mathbf{A}-\mathbf{F}$ represent different vertebrae, and sub-parts $\mathbf{1}$ and $\mathbf{2}$ in each case represent the anterior and leftlateral views respectively. A. The diplodocid Diplodocus carnegii CM 84, 8th dorsal vertebra: A1 anterior, modified from Hatcher (1901:plate VIII), A2 right lateral reversed, modified from Hatcher (1901:plate VII). B. The rebbachisaurid Rebbachisaurus garasbae MNHN MRS 1958, posterior dorsal vertebra: B1 anterior, B2 left lateral. C. Xenoposeidon proneneukos NHMUK PV R2095, mid-posterior dorsal vertebra: C1 anterior, C2 left lateral. D. The camarasaurid Camarasaurus supremus AMNH 5760/D-X-125, ?10th dorsal vertebra, modified from Osborn and Mook (1923:plate LXX): D1 anterior, D2 left lateral. E. The brachiosaurid Giraffatitan brancai MB.R.3822 (formerly HMN AR1), from a digital model supplied by Heinrich Mallison: E1 anterior, E2 right lateral reversed. F. The titanosaur Yongjinglong datangi GSGM ZH(08)-04, mid-dorsal vertebra, modified from Li et al. (2014:figure 9): F1 anterior, F2 left lateral.

Figure 3. Autapomorphies of Xenoposeidon proneneukos NHMUK PV R2095, mid-posterior dorsal vertebra, highlighted in red. A. anterior view. B. left lateral view. Numbers pertain to the numbering of autapomorphies in the text. 1a, neural arch covers whole of centrum, and $\mathbf{1 b}$ is contiguous with posterior articular facet. 2, neural arch is inclined forward by 30-35 degrees relative to the vertical. 3a, inclined ridge-like lamina marks ventral margin of $\mathbf{3 b}$ broad featureless area of bone. 4, large teardrop-shaped anterior fossa. 5a, vaulted laminae bound this fossa, but are not the medial CPRLs (5b, drawn in finer lines), which continue up to the presumed location of the prezygapophyses. 
645 Figure 4. Centra and neural arches of posterior dorsal vertebrae from two rebbachisaurid 646 sauropods (not to scale), highlighting the distinctive "M" shape formed by laminae on the lateral 647 face of the neural arch. A. NHMUK PV R2095, the holotype and only vertebra of Xenoposeidon 648 proneneukos. B. MNHN MRS 1958, a posterior dorsal vertebra from the holotype specimen of 649 Rebbachisaurus garasbae.

650 Figure 5. NHMUK PV R2095, the holotype and only vertebra of Xenoposeidon proneneukos, in 651

652

653

654

655

656

657

658

659

660

661

662 left anteroventrolateral view, highlighting the three sets of laminae related to the prezygapophyses. The trajectories of the medial CPRLs (which emerge from the neural arch pedicels) and the lateral CPRLs (which intersect with the APCLs) indicate the approximate position of the prezygapophyses. The additional arched laminae form the margins of the large, teardrop-shaped anterior fossa (which is homologous with a CPRF, but should technically not be so called due to its enclosure by laminae other than the mCPRLs), but meet at a position some way below and posterior to the presumed location of the prezygapophyseal facets. Breakage of both medial CPRLs and the left ACPL and PCDL is indicated by cross-hatching. Note that, from this perspective, the lateral CPRL appears to turn a corner where it intersects with the ACPL, such that the posteroventral portion of the lateral CPRL appears contiguous with the dorsal portion of the ACPL. This is an illusion brought about by the eminence at the point of intersection. As always, this is much easier to see in three dimensions (see supplementary file 1).

663 Figure 6. NHMUK PV R2095, the holotype and only vertebra of Xenoposeidon proneneukos, in 664 left lateral view, with interpretative drawings. A. The incorrect interpretation of the laminae from Taylor and Naish (2017:figure 4A), with identifying captions greyed out since they are largely incorrect. B. The revised interpretation of the same laminae, based on the similar arrangement in Rebbachisaurus garasbae. Scale bar $=200 \mathrm{~mm}$.

668

Figure 7. NHMUK PV R2095, the holotype and only vertebra of Xenoposeidon proneneukos, in left lateral view, interpreted as a rebbachisaurid. This interpretation is modelled primarily on MNHN MRS 1958, a posterior dorsal vertebra from the holotype specimen of Rebbachisaurus

672 garasbae. The CPOL passes through a sheetlike PCDL, as in Rebbachisaurus; but the lateral

673 CPRL forms a cross-shaped junction with the ACPL, each of these laminae equally interrupting the trajectory of the other. Scale bar $=200 \mathrm{~mm}$.

Supplementary Files

Supplementary file 1. Three-dimensional surface model (11 million polygons) of NHMUK PV R2095, the holotype and only vertebra of Xenoposeidon proneneukos. A 3D polygon mesh file

677 was created by Heinrich Mallison (Palaeo3D) in Agisoft Photoscan Pro version 1.3.0

678 (agisoft.com), from 95 high resolution digital photographs by the author. All 95 images aligned, and resulted in a dense point cloud at maximum resolution of 20,900,043 points and 44,871,128

680 polygons. Scaling was based on a single $10 \mathrm{~cm}$ scale bar created from a high quality scale bar

681

682

683 placed in the pictures with the specimen. Available from https://doi.org/10.6084/m9.figshare.5605612.v2 and viewable online at https://sketchfab.com/models/7f88203e0bbb49a194cb254ab05c4b22

684 Supplementary file 2. Rotating video, rendered in Rhinoceros 5.0, of three-dimensional surface model (11 million polygons) of NHMUK PV R2095, the holotype and only vertebra of Xenoposeidon proneneukos. A 3D polygon mesh file was created by Heinrich Mallison (Palaeo3D) in Agisoft Photoscan Pro version 1.3.0 (agisoft.com), from 95 high resolution digital 
688 photographs by the author. All 95 images aligned, and resulted in a dense point cloud at 689 maximum resolution of 20,900,043 points and 44,871,128 polygons. Scaling was based on a 690 single $10 \mathrm{~cm}$ scale bar created from a high quality scale bar placed in the pictures with the 691 specimen. Available from https://www.youtube.com/watch?v=2as1Y76uUAA

692 


\section{Figure 1}

NHMUK R2095, the holotype and only vertebra of Xenoposeidon proneneukos, shown from all six cardinal directions.

NHMUK R2095, the holotype and only vertebra of Xenoposeidon proneneukos, shown from all six cardinal directions. Top row: A. dorsal view, with anterior to the left. Middle row, left to right: B. anterior, C. left lateral, D. posterior and E. right lateral view. Bottom row: F. ventral view, with anterior to the left. Scale bar $=200 \mathrm{~mm}$.
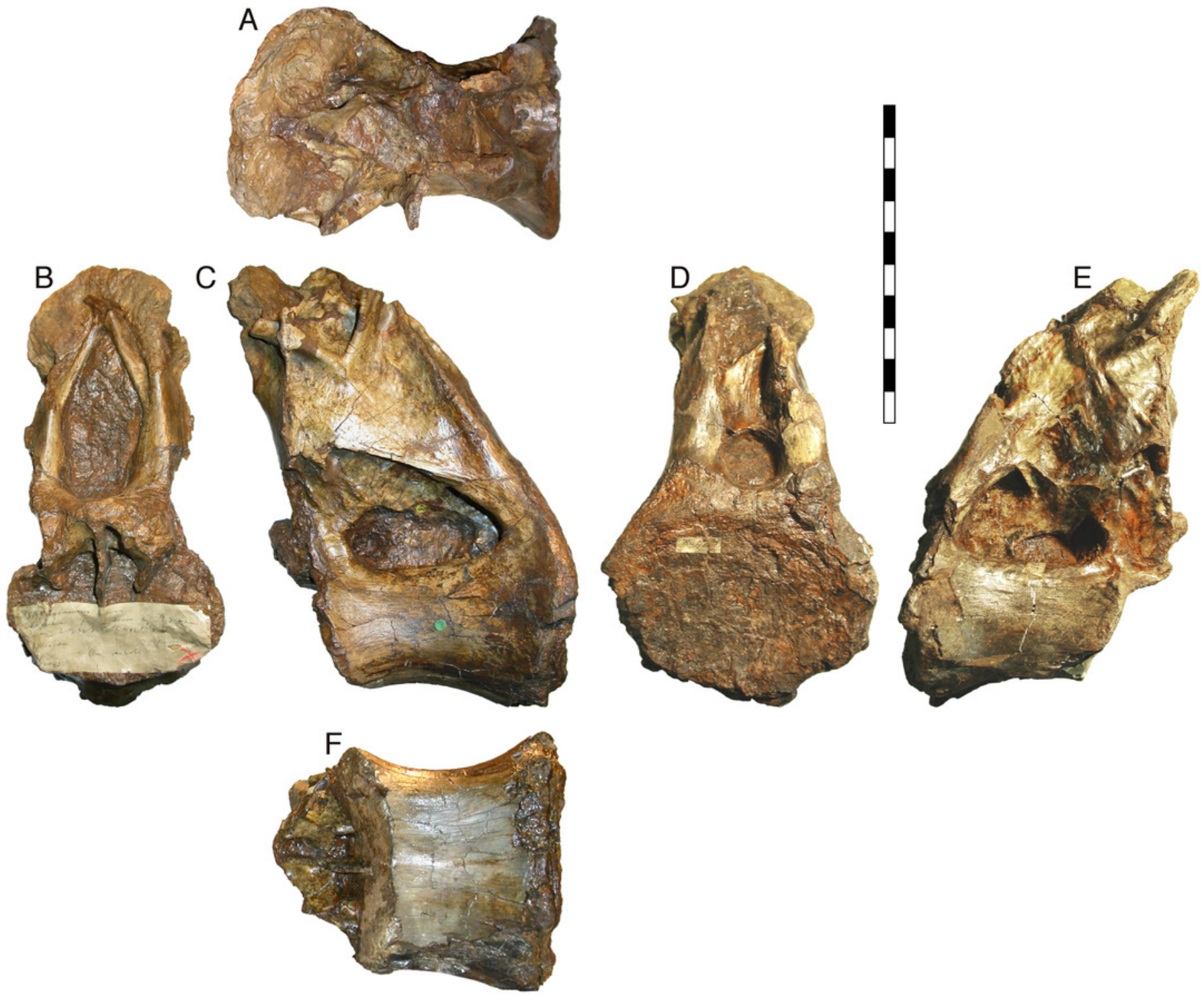


\section{Figure 2}

Comparative morphology of mid-posterior dorsals from six sauropods: Xenoposeidon and five representatives of major groups.

Comparative morphology of mid-posterior dorsals from six sauropods: Xenoposeidon and five representatives of major groups. Each vertebra is shown in anterior and left lateral (or right lateral reversed) views, scaled to the same centrum height. A. The diplodocid Diplodocus carnegii CM 84, 8th dorsal vertebra: A1 anterior, modified from Hatcher (1901:plate VIII), A2 right lateral reversed, modified from Hatcher (1901:plate VII). B. The rebbachisaurid Rebbachisaurus garasbae MNHN MRS 1958, posterior dorsal vertebra: B1 anterior, B2 left lateral. C. Xenoposeidon proneneukos NHMUK R2095, mid-posterior dorsal vertebra: C1 anterior, C2 left lateral. D. The camarasaurid Camarasaurus supremus AMNH 5760/D-X-125, ?10th dorsal vertebra, modified from Osborn and Mook (1923:plate LXX): D1 anterior, D2 left lateral. E. The brachiosaurid Giraffatitan brancai MB.R.3822 (formerly HMN AR1), from a digital model supplied by Heinrich Mallison: E1 anterior, E2 right lateral reversed. F. The titanosaur Yongjinglong datangi GSGM ZH(08)-04, mid-dorsal vertebra, modified from Li et al. (2014:figure 9): $\mathbf{F} \mathbf{1}$ anterior, $\mathbf{F} \mathbf{2}$ left lateral. 

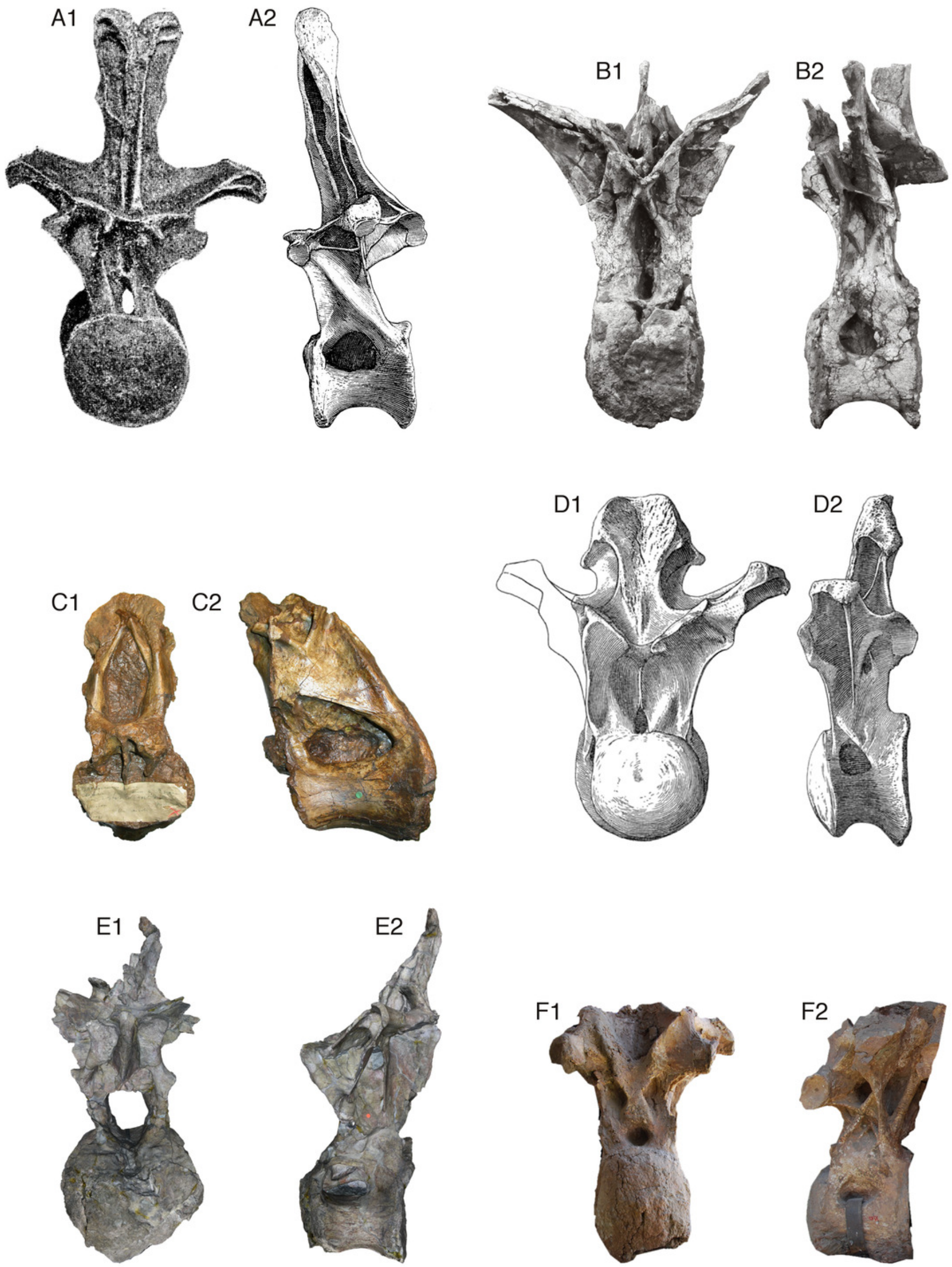


\section{Figure 3}

Autapomorphies of Xenoposeidon proneneukos NHMUK R2095, mid-posterior dorsal vertebra, highlighted in red.

Autapomorphies of Xenoposeidon proneneukos NHMUK R2095, mid-posterior dorsal vertebra, highlighted in red. A. anterior view. B. left lateral view. Numbers pertain to the numbering of autapomorphies in the text. 1a, neural arch covers whole of centrum, and $\mathbf{1} \mathbf{b}$ is contiguous with posterior articular facet. 2, neural arch is inclined forward by 35 degrees relative to the vertical. 3a, inclined ridge-like lamina marks ventral margin of $\mathbf{3} \mathbf{b}$ broad featureless area of bone. 4, large teardrop-shaped anterior fossa. 5a, vaulted laminae bound this fossa, but are not the medial CPRLs (5b drawn in finer lines), which continue up to the presumed location of the prezygapophyses.
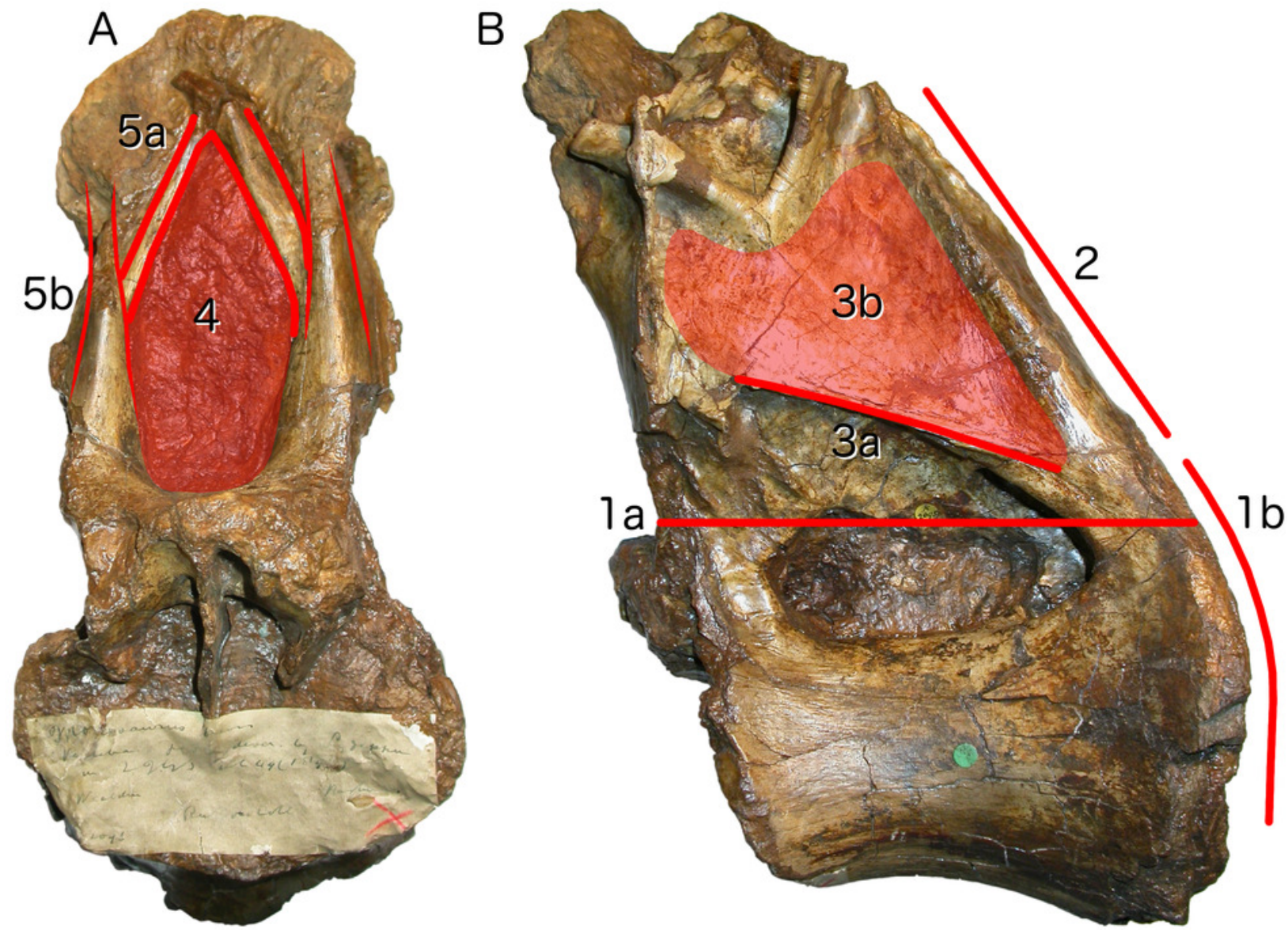


\section{Figure 4}

Centra and neural arches of posterior dorsal vertebrae from two rebbachisaurid sauropods (not to scale), highlighting the distinctive " $\mathrm{M}$ " shape formed by laminae on the lateral face of the neural arch.

Centra and neural arches of posterior dorsal vertebrae from two rebbachisaurid sauropods (not to scale), highlighting the distinctive " $\mathrm{M}$ " shape formed by laminae on the lateral face of the neural arch. A. NHMUK R2095, the holotype and only vertebra of Xenoposeidon proneneukos. B. MNHN MRS 1958, a posterior dorsal vertebra from the holotype specimen of Rebbachisaurus garasbae. 
A

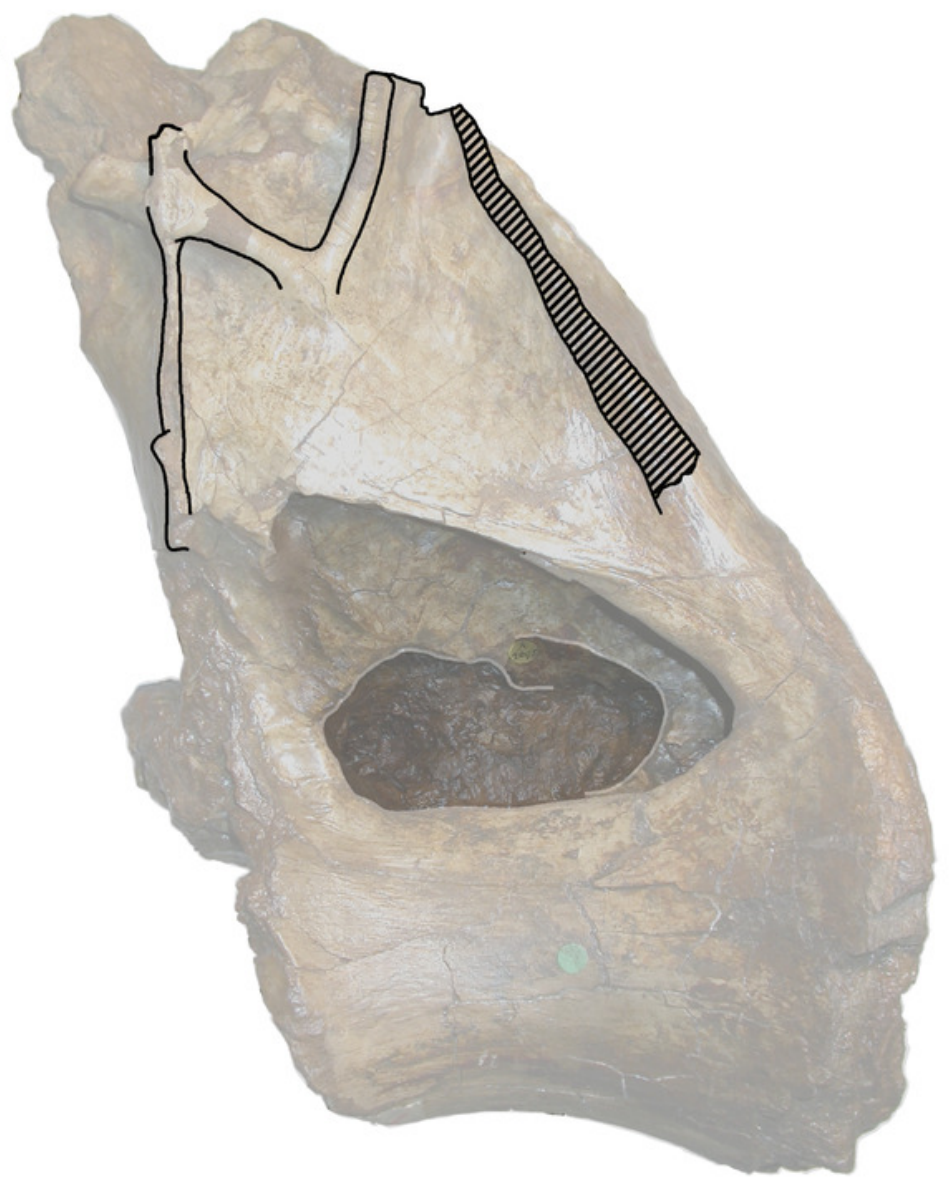

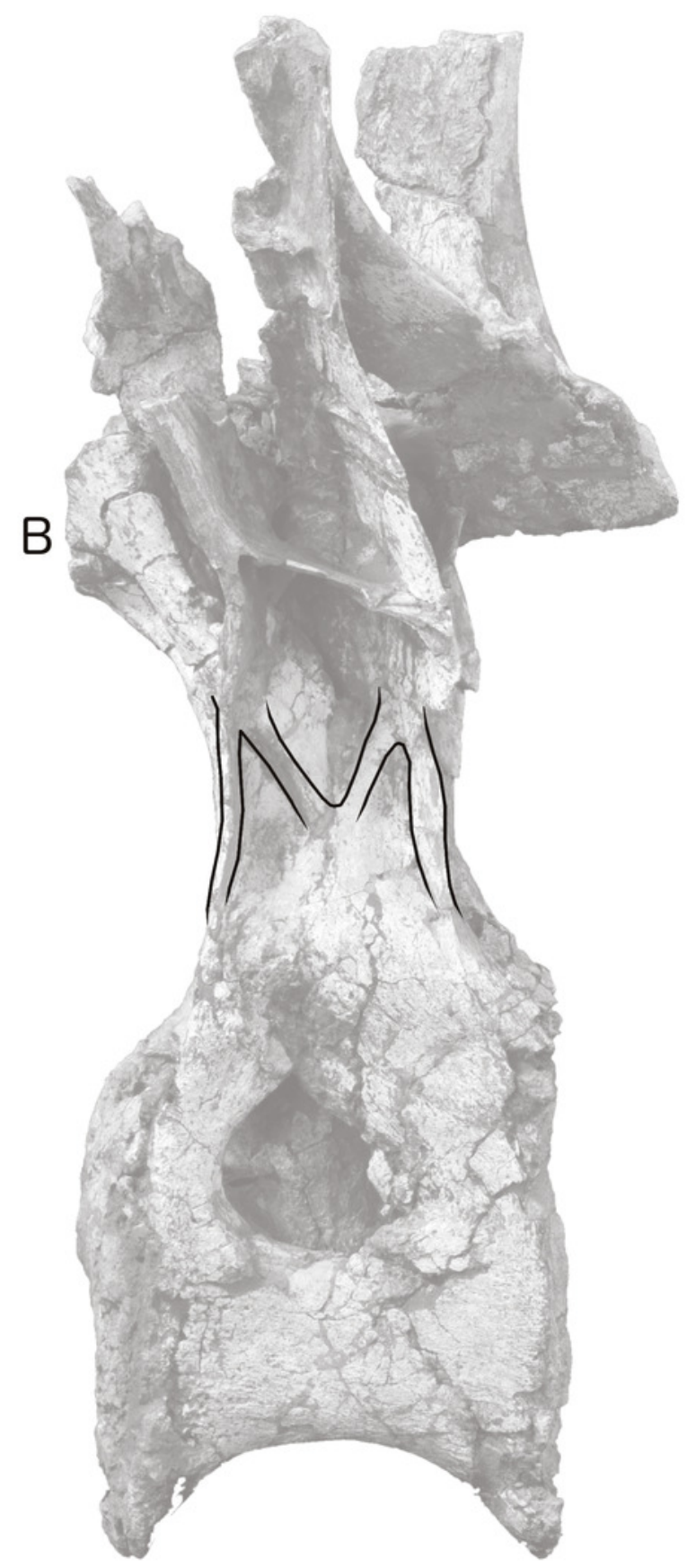




\section{Figure 5}

NHMUK R2095, the holotype and only vertebra of Xenoposeidon proneneukos, in left anteroventrolateral view, highlighting the three sets of laminae related to the prezygapophyses.

NHMUK R2095, the holotype and only vertebra of Xenoposeidon proneneukos, in left anteroventrolateral view, highlighting the three sets of laminae related to the prezygapophyses. The trajectories of the medial CPRLs (which emerge from the neural arch pedicels) and the lateral CPRLs (which intersect with the APCLs) indicate the approximate position of the prezygapophyses. The additional arched laminae form the margins of the large, teardrop-shaped CPRF, but meet at a position some way below and posterior to the presumed location of the prezygapophyseal facets. Breakage of both medial CPRLs and the left $A C P L$ and PCDL is indicated by cross-hatching. Note that, from this perspective, the lateral CPRL appears to turn a corner where it intersects with the ACPL, such that the posteroventral portion of the lateral CPRL appears contiguous with the dorsal portion of the ACPL. This is an illusion brought about by the eminence at the point of intersection. As always, this is much easier to see in three dimensions (see supplementary file 1). 


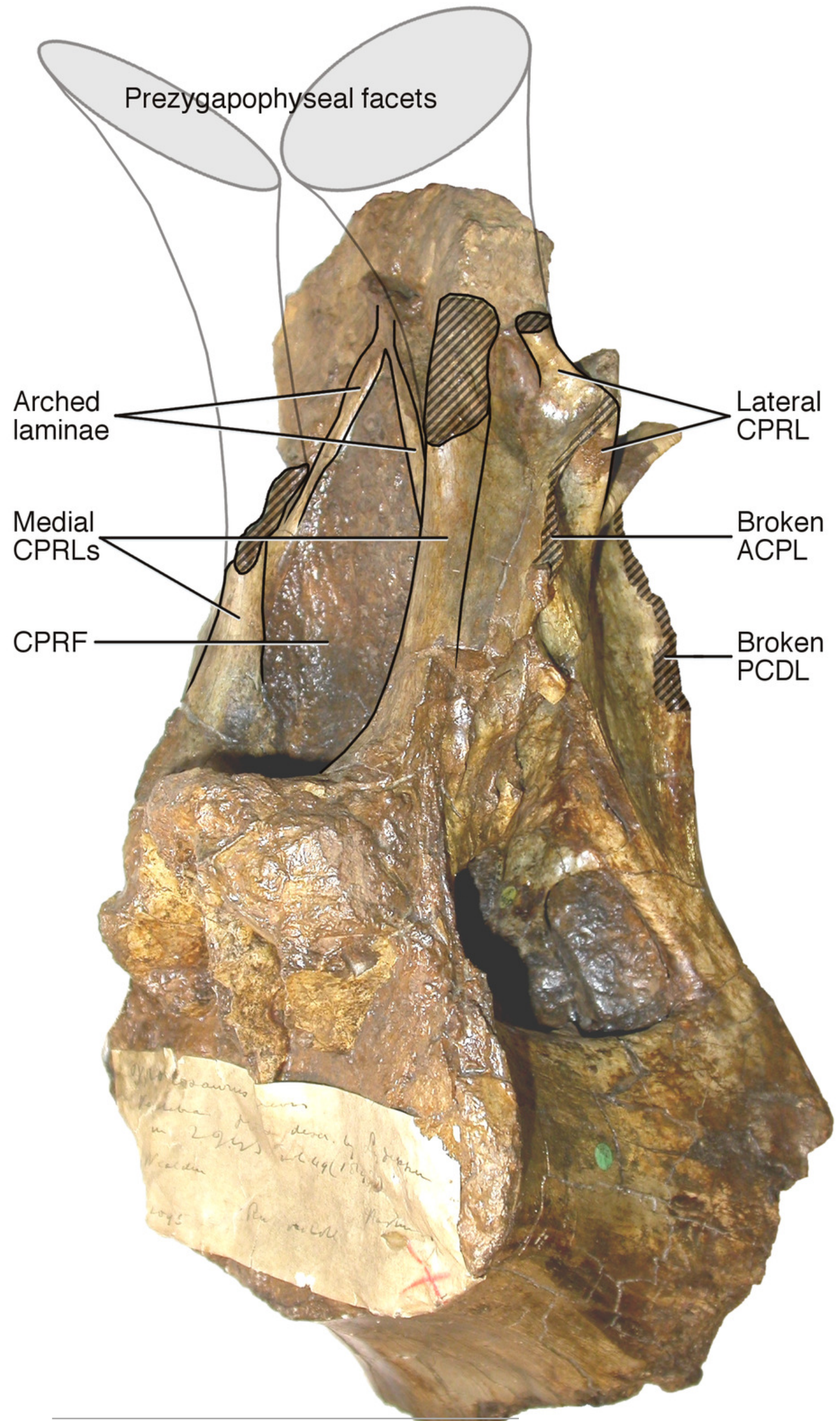




\section{Figure 6}

NHMUK R2095, the holotype and only vertebra of Xenoposeidon proneneukos, in left lateral view, with interpretative drawings.

NHMUK R2095, the holotype and only vertebra of Xenoposeidon proneneukos, in left lateral view, with interpretative drawings. A. The incorrect interpretation of the laminae from Taylor and Naish (2017:figure 4A), with identifying captions greyed out since they are largely incorrect. B. The revised interpretation of the same laminae, based on the similar arrangement in Rebbachisaurus garasbae. Scale bar $=200 \mathrm{~mm}$.
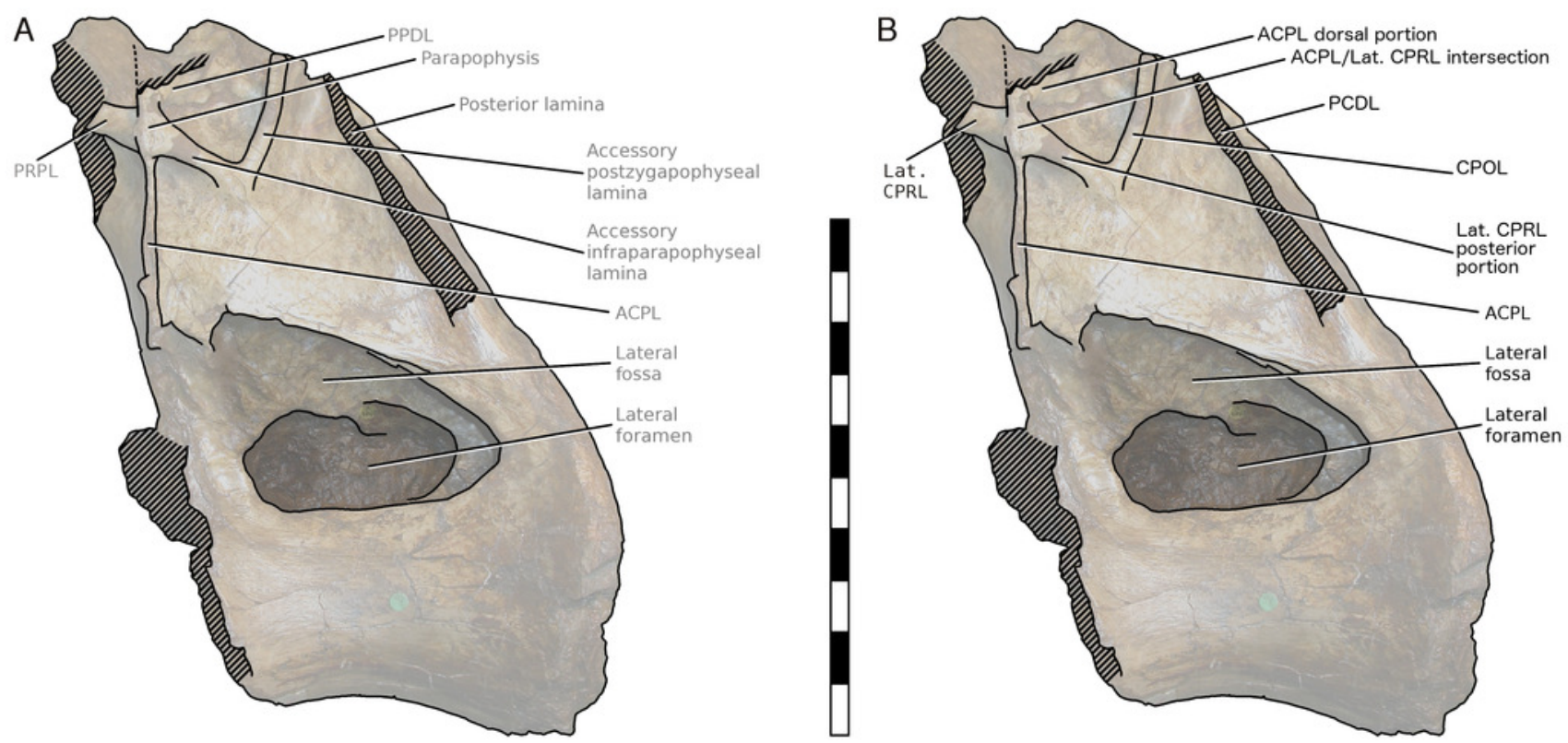


\section{Figure 7}

NHMUK R2095, the holotype and only vertebra of Xenoposeidon proneneukos, in left lateral view, interpreted as a rebbachisaurid.

NHMUK R2095, the holotype and only vertebra of Xenoposeidon proneneukos, in left lateral view, interpreted as a rebbachisaurid. This interpretation is modelled primarily on MNHN MRS 1958, a posterior dorsal vertebra from the holotype specimen of Rebbachisaurus garasbae. The CPOL passes through a sheetlike PCDL, as in Rebbachisaurus; but the lateral CPRL forms a cross-shaped junction with the ACPL, each of these laminae equally interrupting the trajectory of the other. Scale bar $=200 \mathrm{~mm}$. 


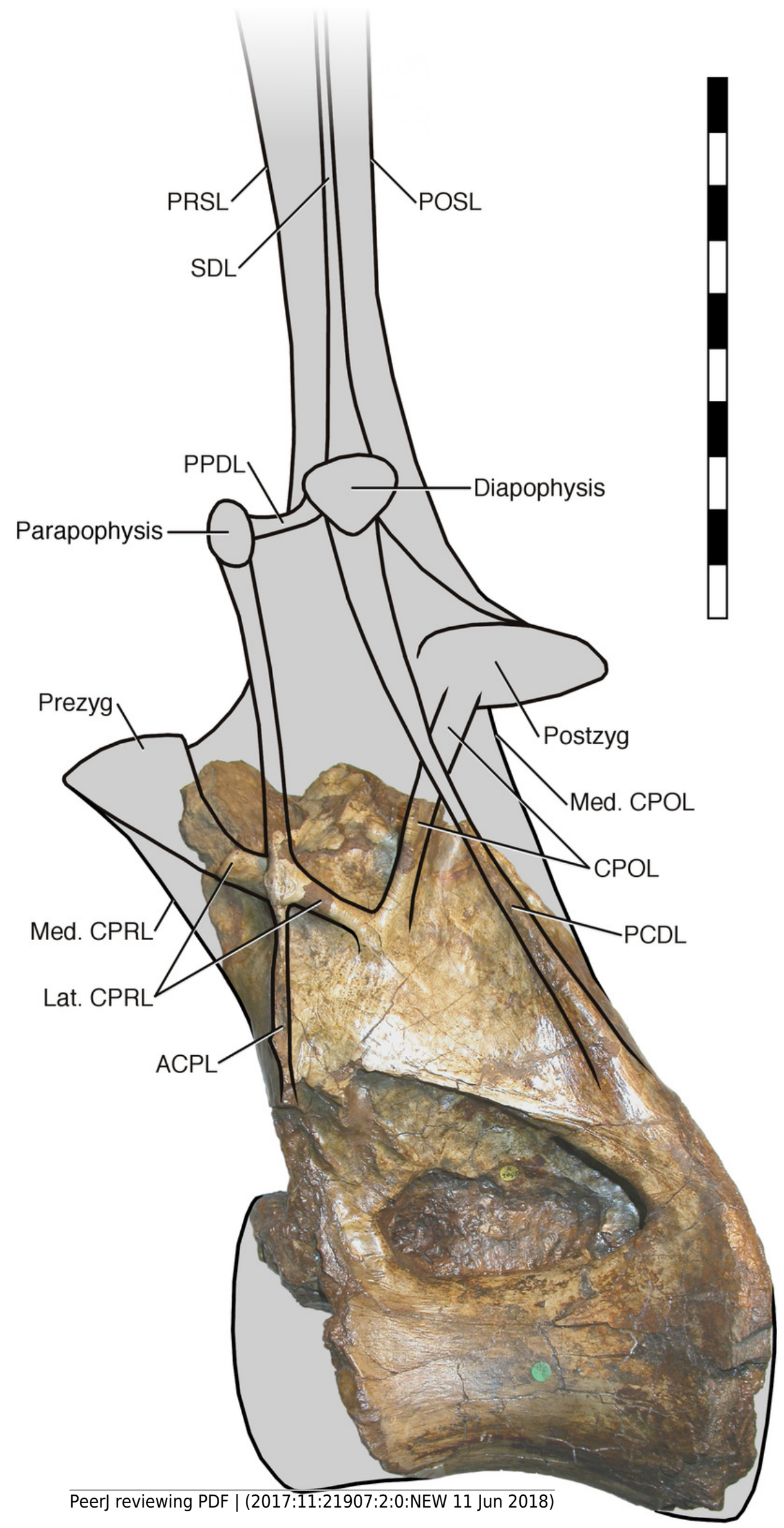

